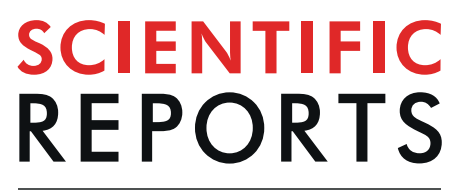

\title{
Temporal variations of ambient air pollutants and meteorological influences on their concentrations in Tehran during 2012-2017
}

Fatemeh Yousefian ${ }^{1,2}$, Sasan Faridi ${ }^{1,2}$, Faramarz Azimi ${ }^{3}$, Mina Aghaei ${ }^{1}$, Mansour Shamsipour ${ }^{4}$, KamyarYaghmaeian ${ }^{1 *}$ \& Mohammad Sadegh Hassanvand ${ }^{2 *}$

We investigated temporal variations of ambient air pollutants and the influences of meteorological parameters on their concentrations using a robust method; convergent cross mapping; in Tehran (20122017). Tehran citizens were consistently exposed to annual $\mathrm{PM}_{2.5}, \mathrm{PM}_{10}$ and $\mathrm{NO}_{2}$ approximately 3.0-4.5, 3.5-4.5 and 1.5-2.5 times higher than the World Health Organization air quality guideline levels during the period. Except for $\mathrm{O}_{3}$, all air pollutants demonstrated the lowest and highest concentrations in summertime and wintertime, respectively. The highest $\mathrm{O}_{3}$ concentrations were found on weekend (weekend effect), whereas other ambient air pollutants had statistically significant $(P<0.05)$ daily variations in which higher concentrations were observed on weekdays compared to weekend (holiday effect). Hourly $\mathrm{O}_{3}$ concentration reached its peak at 3.00 p.m., though other air pollutants displayed two peaks; morning and late night. Approximately $45 \%$ to $65 \%$ of AOI values were in the subcategory of unhealthy for sensitive groups and $\mathrm{PM}_{2.5}$ was the responsible air pollutant in Tehran. Amongst meteorological factors, temperature was the key influencing factor for $\mathrm{PM}_{2.5}$ and $\mathrm{PM}_{10}$ concentrations, while nebulosity and solar radiation exerted major influences on ambient $\mathrm{SO}_{2}$ and $\mathrm{O}_{3}$ concentrations. Additionally, there is a moderate coupling between wind speed and $\mathrm{NO}_{2}$ and $\mathrm{CO}$ concentrations.

The constructed Global Exposure Mortality Model by Burnett et al. (2018) estimated that exposure to ambient air pollution in 2015 was approximately responsible for nine million premature deaths globally ${ }^{1}$. Ambient air pollution exposure-related health effects mainly occurred in megacities of developing countries because of high ambient air pollutant concentrations ${ }^{2}$. Tehran as the capital and most populous city of Iran has faced intense ambient air pollution, particularly criteria air pollutants $\left(\mathrm{PM}_{10}, \mathrm{PM}_{2.5}, \mathrm{O}_{3}, \mathrm{NO}_{2}, \mathrm{SO}_{2}\right.$ and $\left.\mathrm{CO}\right)$, in the last two decades due to unsustainable development of industrialization and urbanization, the ever-growing automotive fleet and their emissions alongside ineffective national ambient air quality standards and Middle Eastern dust storm ${ }^{3-6}$. In fact, ambient air pollution in Tehran has become one of the most challenging environmental issues for Iranian central government, authorities, policy-makers, Tehran citizens, national and international researchers ${ }^{3,7-9}$. It is estimated that approximately $98 \%$ of $\mathrm{CO}, 75 \%$ of $\mathrm{PM}_{2.5}$ and $46 \%$ of $\mathrm{NO}_{\mathrm{X}}$ are emitted from mobile sources in Tehran ${ }^{4,10}$, confirming the need for appropriate sustainable control policies and regulations against vehicular traffic, such as mandatory applying state-of-the-art technologies to reduce road traffic-related emissions, and more effective and serious implementation of transportation policies ${ }^{4}$. Also, energy conversion (e.g. power plants and oil refineries) is responsible for $25 \%$ of $\mathrm{NO}_{\mathrm{X}}$ and $20 \%$ of particulate matter emissions ${ }^{11}$. Approximately $23 \%$ of $\mathrm{NO}_{\mathrm{X}}$ originated from the household and commercial sectors ${ }^{11}$. Furthermore, $\mathrm{SO}_{2}$ is the only ambient air pollutant dominated by emissions from industrial activities (about 22\%), power plants and oil refineries (68\%), while the rest of $\mathrm{SO}_{2}$ emissions comes from mobile sources ${ }^{10}$. In urban areas, ambient $\mathrm{O}_{3}$ is generated via a series of complex photochemical reactions involving solar radiation (SR) and $\mathrm{O}_{3}$-precursors, e.g., $\mathrm{NO}_{\mathrm{X}}, \mathrm{CO}$, reactive volatile organic

${ }^{1}$ Department of Environmental Health Engineering, School of Public Health, Tehran University of Medical Sciences, Tehran, Iran. ${ }^{2}$ Center for Air Pollution Research (CAPR), Institute for Environmental Research (IER), Tehran University of Medical Sciences, Tehran, Iran. ${ }^{3}$ Nutrition Health Research Centre, Department of Environment Health, School of Health and Nutrition, Lorestan University of Medical Sciences, Khorramabad, Iran. ${ }^{4}$ Department of Research Methodology and Data Analysis, Institute for Environmental Research, Tehran University of Medical Sciences, Tehran, Iran. *email: KYaghmaeian@gmail.com; Hassanvand@tums.ac.ir 
compounds (VOCs) and methane ${ }^{12}$. Similar to other $\mathrm{O}_{3}$-precursors $\left(\mathrm{NO}_{\mathrm{x}}\right.$ and $\mathrm{CO}$ ) in Tehran, VOCs are mainly emitted from mobile sources (approximately $86 \%)^{4,13}$. To date, numerous investigations have been conducted in Tehran that have focused on various issues of ambient air pollution, including investigation of chemical characterization of ambient particulate matter ${ }^{14,15}$ and their toxicological effects ${ }^{16}$, ambient particulate matter source apportionment ${ }^{10}$, health effects of ambient air pollutants ${ }^{3,17}$ and emission inventory of ambient air pollutants ${ }^{7}$. Although remarkable investigations have been conducted, a comprehensive and in-depth understanding temporal variability of all criteria air pollutants as well as the meteorological influences on their concentrations using a robust method remains unclear in Tehran to date. Firstly, previous investigations mainly considered temporal variability of one or two ambient air pollutants and their correlations with meteorological parameters (MPs) using Pearson or Spearman correlation analysis. Secondly, since various MPs interact closely with each other, the commonly used Pearson or Spearman correlation analysis may lead to biased findings ${ }^{18}$. Advanced approaches, including the convergent cross mapping (CCM) method and Granger causality test, instead of a simple correlation analysis, should be comprehensively utilized to quantify the influence of MPs on ambient air pollutant concentrations $^{19}$. Finally, exploring temporal variations of all criteria air pollutants with proper approaches and their casual relationships with MPs are crucial to reveal whether the implemented air pollution control measures were successful or not, as well as can be used as a beneficial tool for air quality policy-and decision-makers to modify and revise air pollution controls strategies in order to more mitigate air pollutant concentrations and their health outcomes ${ }^{20,21}$. Therefore, this study was designed to investigate (1) temporal variations (annual, seasonal, monthly, daily and hourly) of criteria air pollutants; $\mathrm{PM}_{2.5}, \mathrm{PM}_{10}, \mathrm{NO}_{2}, \mathrm{O}_{3}, \mathrm{SO}_{2}$, and $\mathrm{CO}$; as well as the long-term trend of air quality index (AQI) and (2) the influence of MPs such as temperature, precipitation, wind speed (WS), SR, relative humidity (RH), and nebulosity on the concentrations of ambient air pollutants in Tehran during the study period from 2012 to 2017.

\section{Results and Discussion}

Overview and annual trends of criteria air pollutant concentrations. Figure 1(a-f) and Table S1 compare the annual mean concentrations of six criteria air pollutants in Tehran during the study period from 2012 to 2017. The highest annual $\mathrm{PM}_{2.5}, \mathrm{O}_{3}$, and $\mathrm{SO}_{2}$ mean concentration was recorded in 2012 with approximately $36.0 \mu \mathrm{g} \mathrm{m}^{-3}, 20.7$ and $20.4 \mathrm{ppb}$, whereas the highest annual mean concentration of $\mathrm{PM}_{10}\left(90.0 \mu \mathrm{g} \mathrm{m}^{-3}\right), \mathrm{NO}_{2}(53.3$ $\mathrm{ppb})$ and $\mathrm{CO}(2.7 \mathrm{ppm})$ was found in 2013, 2017 and 2014, respectively. Also, the lowest annual mean concentration of $\mathrm{PM}_{2.5}$ and $\mathrm{O}_{3}, \mathrm{NO}_{2}$ and $\mathrm{CO}, \mathrm{PM}_{10}$, and $\mathrm{SO}_{2}$ was observed in 2016, 2012, 2014, and 2017 with approximately $30.0 \mu \mathrm{g} \mathrm{m}^{-3}$ and $17.5 \mathrm{ppb}, 35.6 \mathrm{ppb}$ and $2.5 \mathrm{ppm}, 79 \mu \mathrm{g} \mathrm{m}^{-3}$, and $7.9 \mathrm{ppb}$, respectively. Unfortunately, annual $\mathrm{PM}_{10}$, $\mathrm{PM}_{2.5}$, and $\mathrm{NO}_{2}$ mean concentrations were higher than the World Health Organization air quality guideline levels (20 and $10 \mu \mathrm{g} \mathrm{m}^{-3}$ for $\mathrm{PM}_{10}$ and $\mathrm{PM}_{2.5}$, and $22 \mathrm{ppb}$ for $\mathrm{NO}_{2}$ ) during the entire study period (Figure 1a-c).

A glance at the Figure 1a provided reveals that the annual mean $\mathrm{PM}_{10}$ concentrations fluctuated between approximately 78.9 and $89.9 \mu \mathrm{g} \mathrm{m}^{-3}$ and had no a constant downward or upward trend over the entire study period (2012-2017). The non-parametric Mann-Kendall trend test and Sen's slope estimator (MKTT-SSE) confirmed these findings (Table 1). Compared to $\mathrm{PM}_{10}$, annual averages of ambient $\mathrm{PM}_{2.5}$ decreased from about $36.0 \mu \mathrm{g} \mathrm{m}^{-3}$ in 2012 to $31.5 \mu \mathrm{g} \mathrm{m}^{-3}$ in 2017; a decline of 14.3 percent from 2012 to 2017 . On the other hand, according to MKTT-SSE, annual $\mathrm{PM}_{2.5}$ declined significantly $(\mathrm{P}<0.05)$ with the slope of $1.2 \mu \mathrm{g} \mathrm{m}^{-3}$ per year (Table 1). During the period from 2012 to 2017, among all ambient gaseous air pollutants, only annual mean concentration of $\mathrm{NO}_{2}$ and $\mathrm{SO}_{2}$ revealed a constant upward and downward trend, respectively (Figure 1c,d and Table 1). Annual mean $\mathrm{SO}_{2}$ concentrations declined from approximately 20.4 to 7.9 ppb between 2012 and 2017; a sharp fall of 61.5 percent (Figure 1d). Regarding MKTT-SSE, $\mathrm{SO}_{2}$ decreased statistically significant $(\mathrm{P}<0.05)$ with the slope of $2.5 \mathrm{ppb}$ per year (Table 1). By contrast, annual $\mathrm{NO}_{2}$ displayed a considerable upward trend in which its annual mean concentrations increased to approximately $53.3 \mathrm{ppb}$ in 2017; an overall increase of 33 percent between 2012 and 2017. Based on MKTT-SSE, $\mathrm{NO}_{2}$ increased significantly $(\mathrm{P}<0.05)$ with the slope of 4.2 ppb per year (Table 1). For CO (Figure 1e), annual mean concentrations fluctuated at somewhere between 2.5 and $2.7 \mathrm{ppm}$ and showed a statistically non-significant M-shaped pattern (Table 1). Similar to $\mathrm{PM}_{10}$ and $\mathrm{CO}$, ambient $\mathrm{O}_{3}$ had a statistically non-significant fluctuating trend during the study period from 2012 to 2017 (Figure. 1f and Table 1). In summary, the main reasons behind the declining trend of annual $\mathrm{PM}_{2.5}$ and $\mathrm{SO}_{2}$ may be associated with various local air pollution control policies such as implementation of rules on emission standards and fuel quality enhancement (e.g. low sulfur diesel), phasing out of old/carburetor equipped vehicles, the mandatory use of diesel particulate filter, vehicle catalyst replacement, adopting EURO norms, conversion of diesel engines to compressed natural gas, as well as the extending public transportation, particularly subway and bus rapid transit ${ }^{7,22,23}$. As reported by Tehran Air Quality Control Company (TAQCC), during the period 2014-2017, the sulfur content of gasoline and diesel distributed in Tehran megacity was decreased from 200 and $7000 \mathrm{ppm}$ to approximately 20 and less than $50 \mathrm{ppm}$, respectively ${ }^{24}$. The rising annual trend of $\mathrm{NO}_{2}$ as one of the most important road traffic emissions can be related to the increase of total number of vehicles in Tehran over time, because the number of registered vehicles in Tehran increased from around 3.8 million in 2012 to approximately 4.5 million in $2015^{7}$. Additionally, in the last decade, Tehran megacity has witnessed construction of approximately $31 \mathrm{~km}$ of highways annually ${ }^{25}$.

Seasonal and monthly patterns of ambient air pollutants. To better reveal the most polluted seasons and months in Tehran, seasonal and monthly concentrations of all ambient air pollutants were investigated during the period 2012-2017. Based on the Iranian calendar, four seasonal periods were examined as following: spring (21 March to 21 June), summer (22 June to 22 September), fall (23 September to 21 December), and winter (22 December to $20 \mathrm{March}$ ). According to regression model analysis (RMA) for seasonal and monthly variations, all ambient air pollutants showed statistically remarkable seasonal and monthly variations (Figure S1(a,b), Figure 2(a,b) and Tables S2 to S8). Ambient $\mathrm{PM}_{2.5}, \mathrm{NO}_{2}, \mathrm{SO}_{2}$ and $\mathrm{CO}$ revealed significantly higher mean concentrations during 

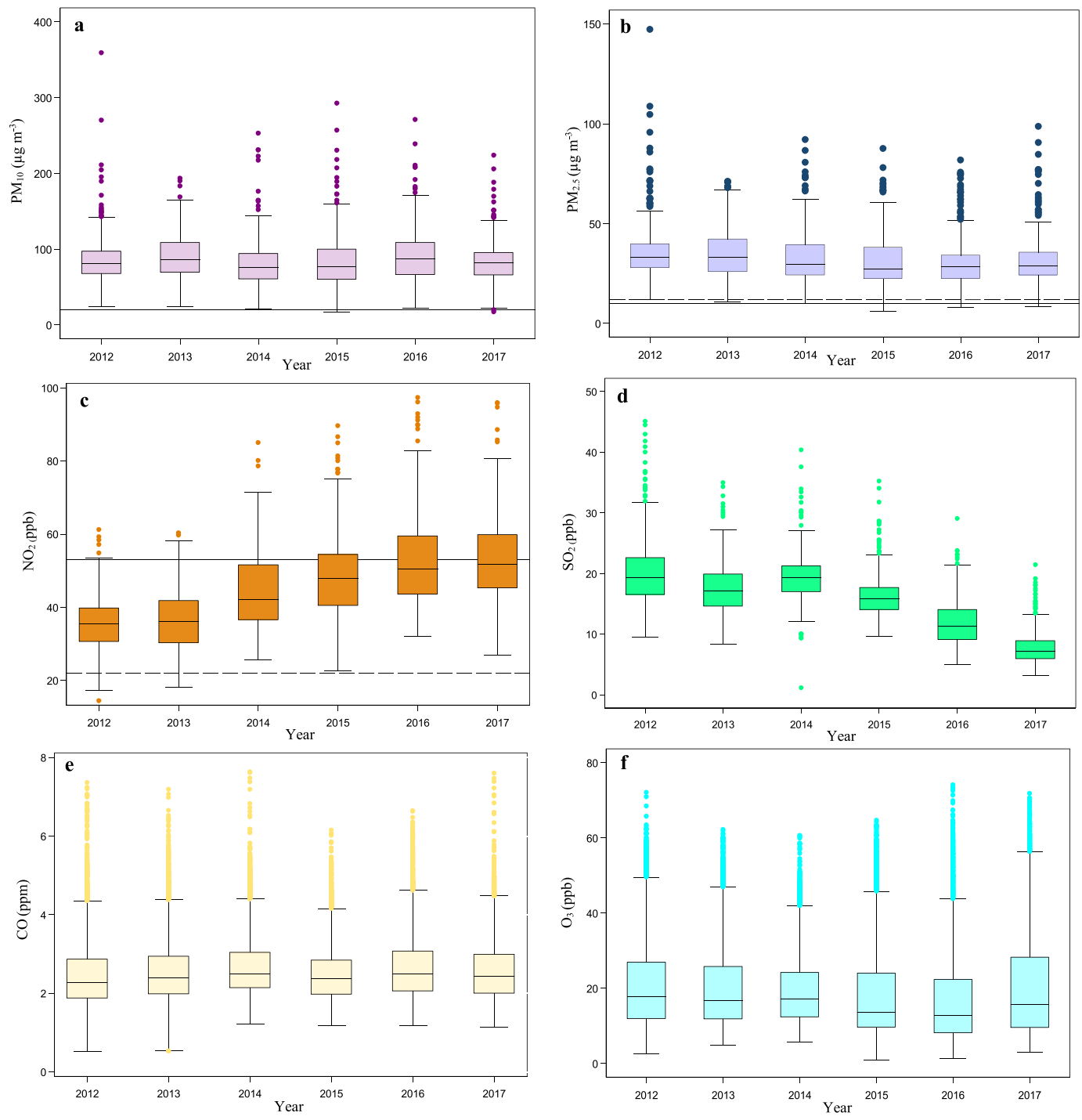

Figure 1. The year-boxplot of $\mathrm{PM}_{10}(\mathbf{a}), \mathrm{PM}_{2.5}(\mathbf{b}), \mathrm{NO}_{2}(\mathbf{c})$, and $\mathrm{SO}_{2}(\mathbf{d})$ based on 24-hr concentrations and CO (e) and $\mathrm{O}_{3}$ (f) based on 8-hr concentrations in Tehran from 2012 to 2017 . Black solid lines and black long-dash lines represent the World Health Organization air quality guideline and Iranian standard levels, respectively.

\begin{tabular}{|c|c|c|}
\hline Air pollutants & $\begin{array}{l}\text { Mann-Kendall } \\
\text { trend }(\mathrm{z}, \mathrm{s})\end{array}$ & $\begin{array}{l}\text { Sen's slope estimate } \\
\text { (concentration }{ }^{\dagger} / \text { year }\end{array}$ \\
\hline $\mathrm{PM}_{10}$ & -1 & -0.42 \\
\hline $\mathrm{PM}_{2.5}$ & $-11^{*}$ & -1.17 \\
\hline $\mathrm{NO}_{2}$ & $15^{*}$ & 4.2 \\
\hline $\mathrm{O}_{3}$ & -7 & -0.62 \\
\hline $\mathrm{SO}_{2}$ & $-13^{*}$ & -2.51 \\
\hline $\mathrm{CO}$ & 5 & 0.02 \\
\hline
\end{tabular}

Table 1. MKTT-SSE for annual mean concentration of ambient air pollutants in Tehran from 2012 to 2017. ( $* \mathrm{P}<0.05,{ }^{\dagger}$ concentration: $\mu \mathrm{g} \mathrm{m}^{-3}$ for $\mathrm{PM}_{10}$ and $\mathrm{PM}_{2.5}, \mathrm{ppb}$ for $\mathrm{O}_{3}, \mathrm{NO}_{2}$ and $\mathrm{SO}_{2}$, and $\mathrm{ppm}$ for $\mathrm{CO}$ ).

colder seasons and months, whereas $\mathrm{PM}_{10}$ showed the highest values during summertime $\left(93.2 \mu \mathrm{g} \mathrm{m}^{-3}\right)$, followed by fall $\left(88.4 \mu \mathrm{g} \mathrm{m}^{-3}\right)$, winter $\left(83.4 \mu \mathrm{g} \mathrm{m}^{-3}\right)$, and spring $\left(73.4 \mu \mathrm{g} \mathrm{m}^{-3}\right)$ (Figure S1a). The mean concentrations of ambient $\mathrm{PM}_{2.5}\left(\mu \mathrm{g} \mathrm{m}^{-3}\right), \mathrm{NO}_{2}(\mathrm{ppb})$ and $\mathrm{SO}_{2}(\mathrm{ppb})$ were in the order of winter $(36.2,48.1$, and 18.7) $>$ fall $(34.6$, 46.8 , and 14.9) $>$ summer $(32.5,46.1$, and 14.7) $>\operatorname{spring}(27.6,39.4$, and 14.2) (Figure S1a,b). In terms of CO, the highest concentrations were found during fall $(2.8 \mathrm{ppm})$ and wintertime $(2.7 \mathrm{ppm})$, whereas the lowest concentrations were observed during spring $(2.2 \mathrm{ppm})$ and summertime $(2.5 \mathrm{ppm})$. Compared to other gaseous air pollutants, $\mathrm{O}_{3}$ displayed the highest concentrations during the summer and spring months, especially July (26.7 

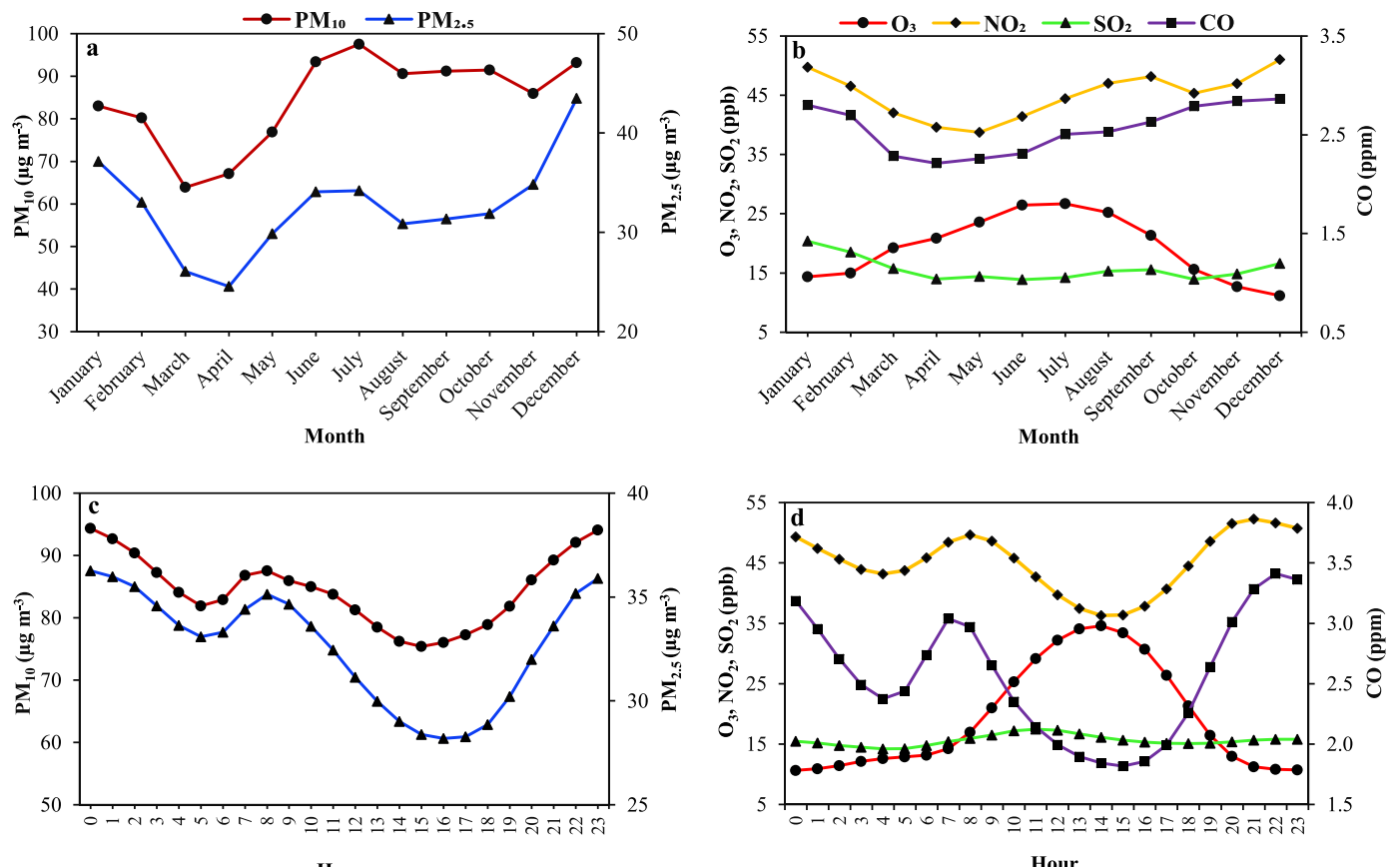

Hour

Hour

Figure 2. Temporal variations of ambient $\mathrm{PM}_{10}, \mathrm{PM}_{2.5}(\mathbf{a}, \mathbf{c})$ and $\mathrm{NO}_{2}, \mathrm{O}_{3}, \mathrm{SO}_{2}, \mathrm{CO}(\mathbf{b}, \mathbf{d})$ concentrations in Tehran during the study period (2012-2017).

ppb), when SR (Figure S2a), temperature (Figure S2a), hydroxyl radical as the most important oxidant species for the formation of $\mathrm{O}_{3}$, VOCs and photochemical reactions are higher ${ }^{26,27}$. Observed seasonal and monthly patterns for $\mathrm{PM}_{2.5}, \mathrm{NO}_{2}, \mathrm{SO}_{2}$ and $\mathrm{CO}$ can be attributed to a combination of unfavorable meteorological conditions, including stagnant weather, reduced horizontal and vertical WS, higher nebulosity, reduced sunshine time, lower $\mathrm{SR}$, temperature inversion and lower the boundary layer during the coldest seasons and months compared to summer and spring months (Figure S2) ${ }^{28-31}$. In relation to $\mathrm{PM}_{10}$, exactly similar to Ahvaz city, Middle East dust storm was responsible for the peak concentration of $\mathrm{PM}_{10}$ during summer in Tehran ${ }^{11,32-35}$. High concentrations of $\mathrm{PM}_{10}$ during fall and winter months are more likely due to the aforementioned reasons for $\mathrm{PM}_{2.5}, \mathrm{NO}_{2}, \mathrm{SO}_{2}$ and $\mathrm{CO}$ concentrations. Our results, particularly seasonal and monthly variations of gaseous air pollutants, are consistent with the findings reported by S. Squizzato and colleagues (2018) across New York State and the results of R. Li and colleagues (2017) in 187 Chinese cities ${ }^{26,29}$.

Nowruz Persian New Year holidays which late approximately 2 weeks from late March to early April each year are the most notable and the longest holiday in $\operatorname{Iran}^{4,36}$. Consequently, vehicular traffics as the most important emission source of ambient air pollutants, particularly $\mathrm{PM}_{2.5}$ and $\mathrm{NO}_{2}$, reduce considerably in Tehran during this period ${ }^{3,4}$. As expected, during the Nowruz holidays, the concentrations of air pollutants were significantly $(\mathrm{P}<0.05)$ declined compared to the rest of year (Table S9). Moreover, the mean $\mathrm{PM}_{10}, \mathrm{PM}_{2.5}$ and $\mathrm{NO}_{2}$ concentrations as the most notable marker of road traffic emissions were $41.0 \mu \mathrm{g} \mathrm{m}^{-3}, 17.0 \mu \mathrm{g} \mathrm{m}^{-3}$ and $37 \mathrm{ppb}$ during the Nowruz holidays, whereas their concentrations over the rest of year were $86 \mu \mathrm{g} \mathrm{m}^{-3}, 33 \mu \mathrm{g} \mathrm{m}^{-3} \mathrm{and} 45 \mathrm{ppb}$, respectively (Figure S3).

Daily and hourly variations of air pollutants. Figures $2(\mathbf{c}, \mathbf{d})$ and S1(c,d) illustrate hourly and daily variations of ambient air pollutants in Tehran during the study period from 2012 to 2017. A glance at the Figure 2c and Figure S1c provided reveals that not only hourly variations of ambient $\mathrm{PM}_{10}$ and $\mathrm{PM}_{2.5}$ but also daily pattern of them are exactly similar. Here, we considered Saturday to Thursday as weekdays/working days and Friday as weekend ${ }^{3}$. In Tehran, by beginning of the working days, vehicle traffic and other emission sources significantly increase mainly due to rising activity of Tehran citizens and daily commuters from other cities of Iran, about 3.5 million commuters ${ }^{24,25,37}$. Therefore, daily mean concentrations of $\mathrm{PM}_{2.5}$ and $\mathrm{PM}_{10}$ start to increase and reach their peaks at approximately 33.9 and $88.6 \mu \mathrm{g} \mathrm{m}^{-3}$ on Wednesday, respectively. In fact, ambient $\mathrm{PM}_{2.5}$ and $\mathrm{PM}_{10}$ concentrations begin to accumulate on the atmosphere over weekdays and they reach their maximum concentrations on Wednesdays. Not surprisingly, the lowest daily mean concentration of ambient $\mathrm{PM}_{2.5}$ and $\mathrm{PM}_{10}$ was recorded on Fridays with approximately 30.3 and $76.8 \mu \mathrm{g} \mathrm{m}^{-3}$, which is known as the "holiday effect", followed by Saturdays with 31.8 and $82.5 \mathrm{\mu g} \mathrm{m}^{-3}$. Our results are consistent with the findings of Faridi et al., and O. Alizadeh-Choobari et al. in Tehran megacity and the results of Maleki and colleagues in Ahvaz city $3,35,36$. It is interesting to note that the daily pattern of $\mathrm{PM}_{10}$ and $\mathrm{PM}_{2.5}$ in our study is exactly similar to day-to-day variations of vehicle traffic in Tehran reported by S. A. H. hassanpour Matikolaei et al. ${ }^{25}$. In addition to the above-mentioned reason, the decrease of ambient air pollution on Saturdays can be related to the self-purification capacity of atmosphere on weekend. According to RMA, daily $\mathrm{PM}_{2.5}$ and $\mathrm{PM}_{10}$ on working days was statistically significant 

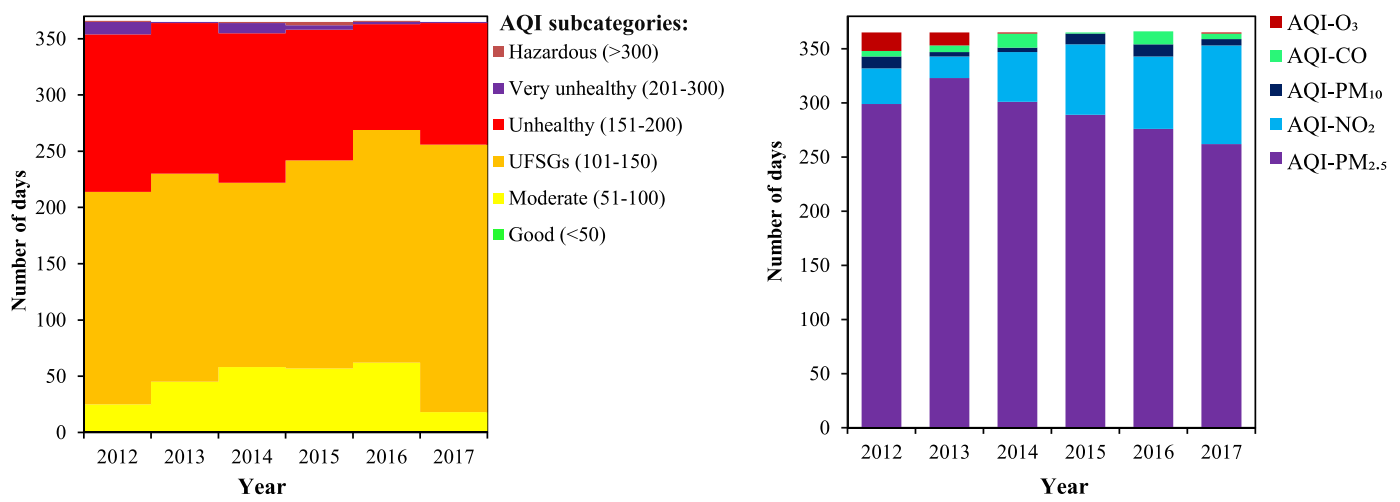

Figure 3. The AQI-subcategories' figures (left) and contribution of each air pollutant in AQI values (right) in Tehran during the study period from 2012 to 2017.

higher compared to weekends during the period from 2012 to 2017 (Tables S10 and S11). In terms of hourly variation of ambient $\mathrm{PM}_{2.5}$ and $\mathrm{PM}_{10}$, we observed two peaks; one in the morning (8:00) and another in the late night (00:00) (Figure 2c, Tables S12 and S13). The morning peaks with 35.1 and $87.5 \mu \mathrm{g} \mathrm{m}^{-3}$ for $\mathrm{PM}_{2.5}$ and $\mathrm{PM}_{10}$ were significantly smaller compared to the peaks observed in the late night (Figure 2c). The morning peak is only likely due to vehicular traffic in the morning, whereas another peak can be related to the traffic of light-duty vehicles in the late afternoon and early evening accompanied by increasing heavy-duty vehicles-related traffic during nighttime (after 22:00) as a traffic restriction, construction/demolition activities and their related-waste transfer and management, open burning of solid waste, switching off the air pollution control equipment at night, secondary particles formation, as well as decreasing boundary layer height ${ }^{3,8,29,36}$. Moreover, as shown in Figure 2c, two valleys are obviously visible for hourly $\mathrm{PM}_{2.5}$ and $\mathrm{PM}_{10}$ in the early morning (from 4:00 to 6:00) and from mid-morning to late afternoon/early evening. The latter valley is most likely owing to increasing boundary layer depth together with reduced traffic-related emissions and the increase of WS ${ }^{38-40}$. Generally speaking, based on RMA (Tables S14 and Figure S4), the nighttime (from 21:00 to 7:00) concentrations of $\mathrm{PM}_{2.5}$ and $\mathrm{PM}_{10}$ were significantly higher in comparison to the daytime (between 8:00 and 20:00) concentrations, which can be explained by the above-mentioned reasons ${ }^{41-43}$. Finally, it is worth noting that hourly patterns of $\mathrm{PM}_{2.5}$; as a notable marker of combustion emissions from road traffic; and $\mathrm{PM}_{10}$ in Tehran are similar to hourly traffic-related emissions, to be exact ${ }^{11}$. As shown in Figure S1d, daily mean concentrations of $\mathrm{NO}_{2}, \mathrm{O}_{3}, \mathrm{SO}_{2}$ and $\mathrm{CO}$ were about constant around a value from Saturday to Thursday, followed by a statistically slight increase in mean concentration of $\mathrm{O}_{3}$ and a statistically small reduction in mean concentrations of $\mathrm{NO}_{2}, \mathrm{SO}_{2}$ and $\mathrm{CO}$ on weekend. These slight decreases and rises of ambient gaseous air pollutants on Friday in comparison to other days of week were statistically significant based on the results of RMA (Tables $\mathbf{S 1 5}$ to S18). The decrease of $\mathrm{NO}_{2}, \mathrm{SO}_{2}$ and CO concentrations at the end of week can be mainly attributed to lower vehicle traffic compared to the other days of week, whereas the increase of $\mathrm{O}_{3}$ as a secondary air pollutant is most likely owing to decreasing $\mathrm{O}_{3}$ destruction by the reduced titration effect of $\mathrm{NO}_{\mathrm{X}}$ and other ambient air pollutant precursors on weekend (Tables $\mathbf{S 1 5}$ to S18) ${ }^{44-46}$. In reality, similar to $\mathrm{PM}_{2.5}, \mathrm{NO}_{2}$ is used as an important marker for combustion emissions, especially from road traffic and its decrease on weekend represents the reduction of traffic ${ }^{40}$. Similar to ambient $\mathrm{PM}_{10}$ and $\mathrm{PM}_{2,5}$, hourly variation of $\mathrm{NO}_{2}$ and $\mathrm{CO}$ clearly exhibited two peaks and two valleys, mainly reflecting the effect of traffic emissions and meteorological conditions on $\mathrm{CO}$ and $\mathrm{NO}_{2}$ during a day ${ }^{24,37,44,47,48}$. After the observed peaks at 7:00 and 8:00, the concentrations of $\mathrm{CO}$ and $\mathrm{NO}_{2}$ started to decrease and reached their lowest concentrations at 14:00 and 15:00 due to a combination of increasing boundary layer height, WS, SR and photochemical reactions in order to produce $\mathrm{O}_{3}$ coupled with decreasing vehicle traffic emissions as evident by decreased ambient $\mathrm{NO}_{2}{ }^{29,45,49}$. Based on RMA, similar to $\mathrm{PM}_{10}$ and $\mathrm{PM}_{2.5}$, the nighttime concentrations of $\mathrm{NO}_{2}$ and $\mathrm{CO}$ were statistically significantly higher than those observed during the daytime, mainly because of the above-mentioned reasons, as well as the lack of photochemical reactions for their destruction and consumption to produce ambient $\mathrm{O}_{3}$ (Tables $\mathrm{S} 19$ to 21) ) $^{45,50-52}$. Furthermore, hourly $\mathrm{O}_{3}$ revealed a sharp mountain-peak-shaped pattern after midday (14:00) owing to higher SR and photochemical reactions in the early afternoon ${ }^{3}$. Unlike other air pollutants, $\mathrm{SO}_{2}$ revealed no specific hourly pattern, though its hourly variation was statistically significant in the vast majority of hours (Table S22). According to RMA, unlike $\mathrm{PM}_{2.5}, \mathrm{PM}_{10}, \mathrm{NO}_{2}$ and $\mathrm{CO}$, the daytime concentration of $\mathrm{SO}_{2}$ was statistically higher than that during nighttime (Figure S4). In terms of the holiday/weekend effects on ambient air pollutant concentrations, our findings are consistent with the findings of Zhang, Y.-L. and Cao, F. (2015) across Yangtze River Delta, the Pearl River Delta and the Beijing-Tianjin-Hebei regions in China ${ }^{53}$, as well as the findings of S. Squizzato and colleagues (2018) across New York State ${ }^{29}$.

AQI and responsible ambient air pollutant. Figure 3 reveals the subcategories of daily AQI values, as well as the contribution of each air pollutant in AQI figures in Tehran between 2012 and 2017. Daily AQI figures were in the range of 63-497 during the period from 2012 to 2017 (Figure 3 and Table S23). Furthermore, the highest daily AQI (497) was found in 2014, whereas the lowest value (63) was recorded in 2016. Unfortunately, we had no AQI value less than 50, as good subclass of AQI, in Tehran during the mentioned period (Figure 3 and Table S24). A glance at the Figure 3 provided shows that the number of unhealthy for sensitive groups' (UFSGs) 
days had a $\mathrm{V}$-shaped pattern over the whole study period, in which the number of days with the subcategory of UFSGs decreased from 189 to 164 days; a slight decrease of 25 days; during the first three years of the study (2012-2014). Afterwards, it increased considerably to 238 in 2017; an overall increase of 53 days. During the first five years (2012-2016) of the study, the number of days with moderate subcategory has more than doubled, from 25 days in 2012 to 62 days in 2016 (Table S24). The MKTT-SSE confirmed this increasing trend (Table S25). Fortunately, unhealthy days for Tehran citizens showed a significant decrease by 46 days between 2012 and 2016 (Table S25). The number of days with very unhealthy and hazardous conditions declined erratically over the entire study period. As can be noticed in Figure 3, all ambient air pollutants, with the exception of $\mathrm{SO}_{2}$, led to decrease air quality status in Tehran during the study period 2012-2017. Moreover, ambient $\mathrm{PM}_{2.5}$ was the most frequent (from 262 to 323 days, approximately between $72.0 \%$ and $88.5 \%$ out of all days each year) major air pollutant in Tehran during the 6-year study from 2012 to 2017, followed by $\mathrm{NO}_{2}$ (20-91 days, approximately from 5\% to $25 \%$ out of all days each year) as the second frequent major ambient air pollutant in Tehran. On the other hand, $\mathrm{PM}_{2.5}$ with $88.5 \%$ out of all days showed the highest contribution in daily AQI figures for 2013 , whereas the lowest contribution for ambient $\mathrm{PM}_{2.5}$ with $72 \%$ out of all days was observed in the year 2017. Compared to $\mathrm{PM}_{2.5}$, the highest contribution for $\mathrm{NO}_{2}$ in daily AQI figures was recorded in 2017, whereas the lowest contribution of $\mathrm{NO}_{2}$ (5\% out of all days) was found in 2013. Overall, $\mathrm{CO}$ and $\mathrm{O}_{3}$ had the lowest contributions in daily AQI in Tehran over the study period (2012-2017) (Figure 3).

The causality effect of individual MPs on six criteria air pollutants. Herein, to avoid the influences from other probable factors and mirage correlations, we utilized a robust causality analysis approach; the CCM method; to extract the influences of different individual MP on ambient air pollutant concentrations. With a comprehensive understanding of interactions between all ambient air pollutants' concentrations and MPs, this study can provide useful results in order to better predict and control ambient air pollution status in Tehran for policy-makers and environmental science researchers. Moreover, previously conducted studies ${ }^{28,54}$ indicated that MPs are one of the most notable factors causing variations of ambient air pollution over a city. Since it is not feasible to present all convergent maps, hereunder, we display six exemplary convergent maps to demonstrate the mechanism of the CCM method (Figure $4 \mathrm{a}-\mathrm{f}$ ). Hence, the rest of causality maps are presented in the supplementary file in detail (Figures S5 to S10). Additionally, it should be noted that in the present study was explained the influences of MPs on ambient air pollutant concentrations and the influences of ambient air pollutant concentrations on MPs were not presented. Also, we examined the correlation analysis between air pollutant concentrations and MPs using Spearman correlation analysis (Table S28) because the CCM analysis cannot show the direction of the influences of MPs on ambient particulate matter and gaseous air pollutants ${ }^{18}$. In fact, the positive/negative direction from Spearman correlation analysis provides a reliable reference for comprehensive understanding the mechanism how MPs influence ambient air pollutant concentrations ${ }^{18}$. Quantified causality of individual MPs on air pollutant concentrations by the CCM method; the $\rho$ value; is a more reliable indicator and can remarkably differ a lot from the Spearman correlation coefficient; the $r$ value. On the other hand, a large $r$ value for a MP may correspond to a much smaller $\rho$ value ${ }^{20}$. Figure 4(a-f) illustrates the quantitative coupling between MPs and air pollutant concentrations by using the CCM method. As shown in Figure 4a, there was a moderate bidirectional coupling between ambient $\mathrm{PM}_{2.5}$ concentrations and temperature ( $\rho$ value $\sim 0.32$ ). According to correlation coefficients (Table S26), temperature demonstrated a negative influence on ambient $\mathrm{PM}_{2.5}$ concentrations with $\mathrm{r}$ value equal to $-0.124^{20}$. In reality, according to the correlation and CCM analysis (Table S26 and Figure 4a), a negative bidirectional coupling between temperature and ambient $\mathrm{PM}_{2.5}$ concentrations was found in Tehran during the study period (2012-2017). Similar to $\mathrm{PM}_{2.5}$, a moderate bidirectional interaction was found between ambient $\mathrm{PM}_{10}$ concentrations and temperature with $\rho$ value equal to 0.28 . The results of the CCM analysis indicated that WS with a $\rho$ value in the range of $0.20-0.25$ had a weak influence on ambient $\mathrm{NO}_{2}$ and $\mathrm{CO}$ concentrations, as illustrated in Figure a(c,d). Additionally, a statistically significantly $(\mathrm{P}<0.05)$ negative correlation was found between WS and ambient $\mathrm{NO}_{2}(-0.28)$ and $\mathrm{CO}(-0.46)$ concentrations, as shown in Table S28. On the other hand, a negative bidirectional coupling between WS and the concentrations of ambient $\mathrm{NO}_{2}$ and $\mathrm{CO}$ was found based on the results of the CCM and Spearman correlation analysis. As expected, SR as the most notable influential MP displayed a moderate to strong influence ( $\rho$ value $\sim 0.60$ ) on ambient $\mathrm{O}_{3}$ concentration (Figure 4e). In this case, based on Table S26, O3 had a high positive correlation with SR (0.55) and temperature ( 0.63). Our findings were found that there was a positive bidirectional coupling between SR and ambient $\mathrm{O}_{3}$ concentrations in Tehran which was consistent with previous study in Beijing ${ }^{18}$. As Figure $\mathbf{4 f}$ demonstrates strong coupling between $\mathrm{SO}_{2}$ concentrations and nebulosity $(\rho$ value $=0.68)$ which is likely due to lower dispersions during temperature inversion and lower the boundary layer in coldest situations. As expected, ambient $\mathrm{SO}_{2}$ concentration had a statistically significantly $(\mathrm{P}<0.05)$ negative correlation with $\mathrm{RH}$ ( $\mathrm{r}$ value equal to -0.15$)$, precipitation $(-0.19)$ and nebulosity $(-0.27)$ as markers of colder status (Table S26).

Recommendations for air quality improvement in Tehran. In Tehran, major sources of criteria air pollutants, with the exception of $\mathrm{O}_{3}$ as a secondary air pollutant, have previously been reported arising from road traffic-related emissions (the highest contribution for $\mathrm{CO}, \mathrm{PM}_{2.5}$ and $\mathrm{NO}_{\mathrm{X}}$ ), industrial activities (as the important emission sources of $\mathrm{SO}_{2}, \mathrm{PM}$ and $\mathrm{NO}_{\mathrm{X}}$ ), energy conversion sector (as another important contributor for $\mathrm{NO}_{\mathrm{X}}$ and $\mathrm{PM}$ emissions and the most notable contributor for $\mathrm{SO}_{2}$ ), as well as household and commercial sectors (as the other contributors for $\mathrm{NO}_{\mathrm{x}}$ emissions) ${ }^{10,11,55}$. Therefore, based on the successful short- and long-term programs in other megacities of developed and developing countries $24,56,57$, we recommend a policy mix in order to improve the air quality situation in Tehran megacity: (1) the heavy- and light-duty vehicles (HDVs and LDVs) replacement program via providing financial incentives to owners of old vehicles to trade them with new/less polluting ones; (2) expanding and improving public transportation (Bus-Raid Transport, Light Rail Transport and metro lines); (3) adopting higher fuel quality standards (Euro 5 and 6); (4) slashing fuel subsidies; (5) incentivizing electric 

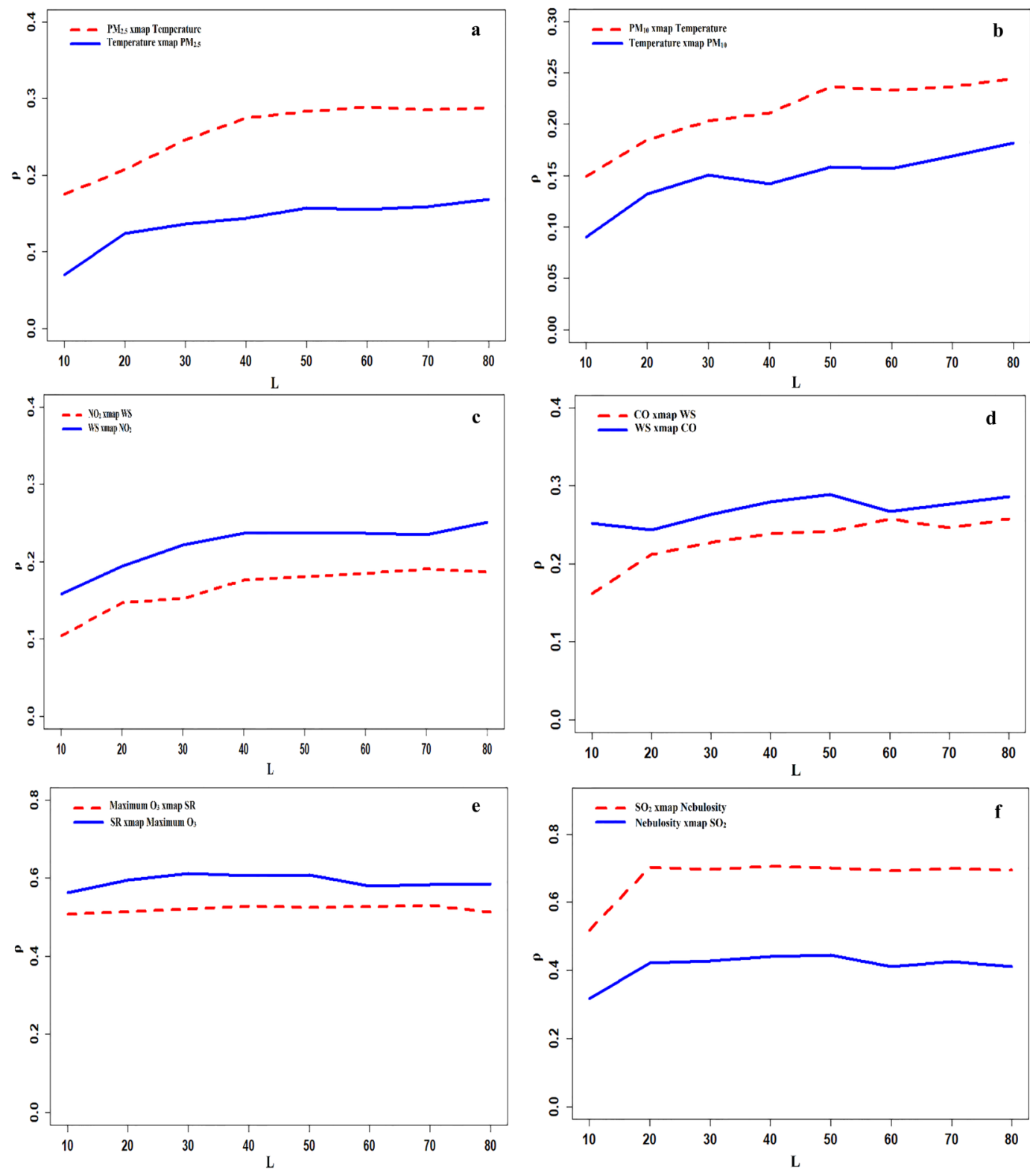

Figure 4. Exemplary CCM test results to show the causality between MPs and the concentrations of ambient $\mathrm{PM}_{2.5}(\mathbf{a}), \mathrm{PM}_{10}(\mathbf{b}), \mathrm{NO}_{2}(\mathbf{c}), \mathrm{CO}(\mathbf{d}), \mathrm{O}_{3}(\mathbf{e})$, and $\mathrm{SO}_{2}(\mathbf{f})$ in Tehran.

and hybrid vehicles, including cars, motorcycles and HDVs; (6) incentivizing non-motorized transport such as walking or cycling; (7) stricter environmental taxes and penalties for industrial activities and energy conversion sectors (e.g., power plants and oil refineries); (8) utilizing sustainable energy technologies in industrial activities and energy conversion sectors and (9) implementation of green tax for household and commercial sectors.

Limitations of this study. As mentioned below, the ambient air quality data were not obtained by the authors of the current work through their own research study rather the ambient air pollutants' data were obtained from Tehran Air Quality Control Company (TAQCC) as a governmental organization that is responsible for ambient air quality monitoring in Tehran. Though we processed and cleaned ambient air quality data obtained from TAQCC, the authors have no information regarding the collocated operations of the instruments, flow calibration, and quality assurance and quality control (QA/QC) at the network level. Also, based on personal communication, the technical officer of air quality monitoring stations (AQMSs) mentioned that they follow QA/ QC procedures exactly similar to the manual of monitoring instruments used at each AQMS.

\section{Methods}

Air quality and meteorological data. Real-time hourly air quality data $\left(\mathrm{PM}_{2.5}, \mathrm{PM}_{10}, \mathrm{NO}_{2}, \mathrm{O}_{3}, \mathrm{SO}_{2}\right.$ and CO) in Tehran between 2012 and 2017 from twenty-one active AQMSs which belong to TAQCC were obtained from the website of http://airnow.tehran.ir/home/DataArchive.aspx. At all AQMSs, ambient $\mathrm{PM}_{2.5}$ and $\mathrm{PM}_{10}$, $\mathrm{O}_{3}, \mathrm{NO}_{2}, \mathrm{SO}_{2}$, and $\mathrm{CO}$ are monitored using the beta-attenuation (Met One BAM-1020, USA; and Environment 
SA, MP 101 M, France), UV-spectrophotometry (Ecotech Serinus 10 Ozone Analyzer, Australia), chemiluminescence (Ecotech Serinus 40 Oxides of Nitrogen Analyzer, Australia), ultraviolet fluorescence (Ecotech Serinus $50 \mathrm{SO}_{2}$ Analyzer, Australia), and non-dispersive infrared absorption (Ecotech Serinus 30 carbon monoxide Analyzer, Australia) methods, respectively (based on personal communication with technical officer of AQMSs from TAQCC). Additionally, the organization follows the QA/QC procedures exactly similar to the manual of monitoring instruments used at each AQMS. For gaseous air pollutants, the instruments are automatically calibrated/checked every 7 days for span and zero calibration. Multipoint calibrations are manually performed approximately every six months according to the manual of monitoring instruments. Additionally, gas analyzers are calibrated following relocation, after any repair or service that might affect their calibration, following an interruption in operation of more than a few days, upon any indication of analyzer malfunction. For ambient PM monitoring instruments, the routine QC and maintenance procedure (nozzle, vane and the PM inlet cleaning, very sharp cut cyclone particle size separator cleaning, leak checking, temperature/pressure/flow calibration) are performed monthly with the exception of the filter tape change, which mainly takes place bi-monthly. Furthermore, additional maintenance steps (the pump muffler cleaning/replacing, the 72-hour zero test and the membrane span foil checking, etc.) are performed every 6 months and every 12 months. Figure S11 shows the spatial distribution of AQMSs. Furthermore, detailed information regarding AQMSs is provided in Table S27. Additionally, meteorological data such as temperature, WS, SR, nebulosity, precipitation, and RH were derived from Tehran Province Metrological Administration. Table S28 illustrates descriptive statistics of meteorological data during entire study period (2012-2017).

Air quality data processing. Prior to analyzing hourly air pollutant concentration for the mentioned objectives earlier, air quality data processing and cleaning were conducted on only AQMSs with hourly data coverage more than $70 \%$ according to Z-score method in order to check and remove outlier hourly data from original hourly time series datasets ${ }^{3,21,58}$. Hourly air quality data were transformed into Z-score and outlier data removed from the subsequent computation according to the following conditions: (1) having an absolute Z-score larger than $4\left(\left|Z_{t}\right|>4\right)$, (2) the increment from the previous hourly value being larger than $9\left(Z_{t}-Z_{t-1}>9\right)$ and (3) the ratio of the hourly value to its centered rolling average of order $3(R A 3)$ being larger than $2\left(Z_{t} / R A 3\left(Z_{t}\right)>2\right)$. The cleaned and processed hourly air quality data were used to account the averages of 1-hr, the running 8-hr and the 24-hr. Hourly concentrations at city-wide were computed according to the hourly data across all included AQMSs for each hour. Then, the running 8-hr average of $\mathrm{O}_{3}$ and the 24-hr average of other air pollutants were calculated for city.

AQI and responsible ambient air pollutant in Tehran. To inform the general public regarding air quality status and its associated health risks, AQI as a daily index is a popular method of air quality knowledge translation $^{59,60}$. This dimensionless index is divided into six subcategories with specified colors as following (Table S29): good (less than 50, green), moderate (51-100, yellow), UFSGs (101-150, orange), unhealthy (151-200, red), very unhealthy (201-300, purple), and hazardous (more than 300, maroon). In AQI approach, a daily 'responsible air pollutant' is identified for city to determine which criteria air pollutant contributes the most to the air quality status degradation. In this work, based on the breakpoints' levels suggested by the U.S. EPA (Table S29), in order to calculate the AQI for $\mathrm{PM}_{2.5}, \mathrm{PM}_{10}, \mathrm{O}_{3}$ and $\mathrm{CO}, 24$-hr average concentrations of $\mathrm{PM}_{2.5}$ and $\mathrm{PM}_{10}$ and 8-hr average concentrations of $\mathrm{O}_{3}$ and $\mathrm{CO}$ were computed from their hourly concentrations. Also, to calculate the AQI related to $\mathrm{NO}_{2}$ and $\mathrm{SO}_{2}$, their hourly concentrations were used. Next, amongst all AQI figures computed for six criteria air pollutants at all AQMSs, the highest AQI was finally considered as the daily AQI and responsible air pollutant for city. The following Eq. (1) was used to compute AQI for each air pollutant ${ }^{59}$.

$$
\mathrm{AQI}_{\mathrm{ap}}=\frac{\mathrm{AQI}_{\mathrm{uc}}-\mathrm{AQI}_{\mathrm{lc}}}{\mathrm{BP}_{\mathrm{uc}}-\mathrm{BP}_{\mathrm{lc}}}\left(\mathrm{C}_{\mathrm{ap}}-\mathrm{BP}_{\mathrm{lc}}\right)+\mathrm{AQI}_{\mathrm{lc}}
$$

where, $A Q I_{a p}$ represents the index for given air pollutant (ap); $A Q I_{u c}$ and $A Q I_{l c}$ represent the index values corresponding to upper and lower of each breakpoint category (BP), respectively; $\mathrm{C}_{\mathrm{ap}}$ is the concentration of each air pollutant; $\mathrm{BP}_{\mathrm{uc}}$ and $\mathrm{BP}_{\mathrm{lc}}$ are the upper and lower concentrations of air pollutant at each breakpoint category, respectively.

Statistical analysis. Temporal characteristics. In order to reveal upward and downward trends (annual mean concentrations of each air pollutant and AQI), their magnitude, as well as whether their magnitude were statistically significant $(\mathrm{P}<0.05)$ or not, the non-parametric MKTT-SSE was run ${ }^{27,38}$. RMA with dummy variables was run to illustrate the differences of mean concentrations at hours, days, months, and seasons for each air pollutant ${ }^{12}$. Similarly, the differences between nighttime and daytime concentrations, as well as the effect of Nowruz holidays on the concentrations of ambient air pollutants compared to the rest of year were assessed using RMA with dummy variables ${ }^{12}$. The mentioned analyses were conducted using State software.

Quantifying the causality influences of MPs on ambient air pollutant concentrations. Due to complicated interactions between MPs and ambient air pollutant concentrations in the atmospheric environment, in fact, it is highly difficult to quantify the causality of MPs on ambient air pollutants through simple Pearson and Spearman correlation analyses ${ }^{18}$. Instead, a robust approach for quantitative causality analysis is proposed by previous studies ${ }^{18,19}$. The CCM method is suitable for detecting causation in time-series data ${ }^{18}$. In this method, by examining the temporal changes of two time-series datasets, their bidirectional coupling can effectively be featured with a convergent map $^{18}$. Furthermore, the CCM approach detects effectively even weak to moderate coupling in time-series variable. If the influence of one variable on another variable is indicated using a convergent curve with rising time 
series length, then the causality is detected. On the other hand, a curve without any convergence demonstrates no causality between the two variables ${ }^{19}$. The predictive skill (defined as the $\rho$ value), ranging from 0 to 1 , shows the strength of influences from one variable on the other ${ }^{19,20}$. This approach cannot show the direction of the influence of MPs on air pollutant concentrations. Therefore, we investigated the positive/negative direction of their influences on air pollutant concentrations using Spearman correlation analysis ${ }^{20}$. To depict the convergent maps of bidirectional causal relationships, the rEDM package in $\mathrm{R}$ software version 3.4 .5 was used.

Received: 10 April 2019; Accepted: 17 November 2019;

Published online: 15 January 2020

\section{References}

1. Burnett, R. et al. Global estimates of mortality associated with long-term exposure to outdoor fine particulate matter. Proceedings of the National Academy of Sciences 115, 9592-9597 (2018).

2. Brook, R. D., Newby, D. E. \& Rajagopalan, S. The global threat of outdoor ambient air pollution to cardiovascular health: time for intervention. JAMA cardiol. 2, 353-354 (2017).

3. Faridi, S. et al. Long-term trends and health impact of PM 2.5 and O 3 in Tehran, Iran, 2006-2015. Environment international 114, 37-49 (2018)

4. Amini, H. et al. Spatiotemporal description of BTEX volatile organic compounds in a Middle Eastern megacity: Tehran study of exposure prediction for environmental health research (Tehran SEPEHR). Environmental pollution 226, 219-229 (2017).

5. Givehchi, R., Arhami, M. \& Tajrishy, M. Contribution of the Middle Eastern dust source areas to PM10 levels in urban receptors: Case study of Tehran, Iran. Atmospheric environment 75, 287-295 (2013).

6. Shamsipour, M. et al. National and sub-national exposure to ambient fine particulate matter (PM2. 5) and its attributable burden of disease in Iran from 1990 to 2016. Environmental Pollution, 113173 (2019).

7. Shahbazi, H., Reyhanian, M., Hosseini, V. \& Afshin, H. The relative contributions of mobile sources to air pollutant emissions in Tehran, Iran: an emission inventory approach. Emission Control Science and Technology 2, 44-56 (2016).

8. Taghvaee, S. et al. Source apportionment of ambient PM 2.5 in two locations in central Tehran using the Positive Matrix Factorization (PMF) model. Science of The Total Environment 628, 672-686 (2018).

9. Faridi, S. et al. Spatial homogeneity and heterogeneity of ambient air pollutants in Tehran. Science of The Total Environment, 134123 (2019).

10. Taghvaee, S. et al. Source apportionment of ambient PM2. 5 in two locations in central Tehran using the Positive Matrix Factorization (PMF) model. Science of The Total Environment 628, 672-686 (2018).

11. Hosseini, V. \& Shahbazi, H. Urban air pollution in Iran. Iranian Studies 49, 1029-1046 (2016).

12. Masiol, M., Squizzato, S., Chalupa, D., Rich, D. Q. \& Hopke, P. K. Spatial-temporal variations of summertime ozone concentrations across a metropolitan area using a network of low-cost monitors to develop 24 hourly land-use regression models. Science of The Total Environment 654, 1167-1178 (2019).

13. Jafari, A. J., Faridi, S. \& Momeniha, F. Temporal variations of atmospheric benzene and its health effects in Tehran megacity (2010-2013). Environmental Science and Pollution Research, 1-10 (2019).

14. Hoseini, M. et al. Characterization and risk assessment of polycyclic aromatic hydrocarbons (PAHs) in urban atmospheric Particulate of Tehran, Iran. Environmental Science and Pollution Research 23, 1820-1832 (2016).

15. Hassanvand, M. S. et al. Characterization of PAHs and metals in indoor/outdoor PM10/PM2. 5/PM1 in a retirement home and a school dormitory. Science of the Total Environment 527, 100-110 (2015).

16. Al Hanai, A. H. et al. Seasonal variations in the oxidative stress and inflammatory potential of PM2. 5 in Tehran using an alveolar macrophage model; The role of chemical composition and sources. Environment international 123, 417-427 (2019).

17. Yousefian, F. et al. Long-term exposure to ambient air pollution and autism spectrum disorder in children: A case-control study in Tehran, Iran. Science of The Total Environment 643, 1216-1222 (2018).

18. Chen, Z. et al. Understanding long-term variations of meteorological influences on ground ozone concentrations in Beijing During 2006-2016. Environmental pollution 245, 29-37 (2019).

19. Chen, Z. et al. Understanding meteorological influences on PM 2.5 concentrations across China: a temporal and spatial perspective. Atmospheric Chemistry and Physics 18, 5343-5358 (2018).

20. Chen, Z. et al. Detecting the causality influence of individual meteorological factors on local PM 2.5 concentration in the Jing-Jin-Ji region. Scientific Reports 7, 40735 (2017).

21. Song, C. et al. Air pollution in China: status and spatiotemporal variations. Environmental Pollution 227, 334-347 (2017).

22. Mohammadiha, A., Malakooti, H. \& Esfahanian, V. Development of reduction scenarios for criteria air pollutants emission in Tehran Traffic Sector, Iran. Science of The Total Environment 622, 17-28 (2018).

23. Arhami, M. et al. Seasonal trends in the composition and sources of PM2. 5 and carbonaceous aerosol in Tehran, Iran. Environmental pollution 239, 69-81 (2018).

24. Heger, M. \& Sarraf, M. (World Bank, 2018).

25. Hassanpour Matikolaei, S. A. H., Jamshidi, H. \& Samimi, A. Characterizing the effect of traffic density on ambient CO, NO2, and PM2. 5 in Tehran, Iran: an hourly land-use regression model. Transportation Letters, 1-11 (2017).

26. Li, R. et al. Spatial and temporal variation of particulate matter and gaseous pollutants in China during 2014-2016. Atmospheric Environment 161, 235-246 (2017).

27. Sicard, P., Serra, R. \& Rossello, P. Spatiotemporal trends in ground-level ozone concentrations and metrics in France over the time period 1999-2012. Environmental research 149, 122-144 (2016).

28. Guo, H., Wang, Y. \& Zhang, H. Characterization of criteria air pollutants in Beijing during 2014-2015. Environmental research 154, 334-344 (2017).

29. Squizzato, S., Masiol, M., Rich, D. Q. \& Hopke, P. K. PM2. 5 and gaseous pollutants in New York State during 2005-2016: Spatial variability, temporal trends, and economic influences. Atmospheric Environment 183, 209-224 (2018).

30. Zhao, S. et al. Spatial patterns and temporal variations of six criteria air pollutants during 2015 to 2017 in the city clusters of Sichuan Basin, China. Science of The Total Environment 624, 540-557 (2018).

31. Darynova, Z. et al. Evaluation of NO2 column variations over the atmosphere of Kazakhstan using satellite data. Journal of Applied Remote Sensing 12, 042610 (2018).

32. Hassanvand, M. S. et al. Indoor/outdoor relationships of PM10, PM2. 5, and PM1 mass concentrations and their water-soluble ions in a retirement home and a school dormitory. Atmospheric Environment 82, 375-382 (2014).

33. Naimabadi, A. et al. Chemical composition of PM10 and its in vitro toxicological impacts on lung cells during the Middle Eastern Dust (MED) storms in Ahvaz, Iran. Environmental Pollution 211, 316-324 (2016).

34. Goudarzi, G., Shirmardi, M., Naimabadi, A., Ghadiri, A. \& Sajedifar, J. Chemical and organic characteristics of PM2. 5 particles and their in-vitro cytotoxic effects on lung cells: The Middle East dust storms in Ahvaz, Iran. Science of The Total Environment 655, 434-445 (2019). 
35. Maleki, H., Sorooshian, A., Goudarzi, G., Nikfal, A. \& Baneshi, M. M. Temporal profile of PM10 and associated health effects in one of the most polluted cities of the world (Ahvaz, Iran) between 2009 and 2014. Aeolian Research 22, 135-140 (2016).

36. Alizadeh-Choobari, O., Bidokhti, A., Ghafarian, P. \& Najafi, M. Temporal and spatial variations of particulate matter and gaseous pollutants in the urban area of Tehran. Atmospheric Environment 141, 443-453 (2016).

37. Taghvaee, S. et al. Source-specific lung cancer risk assessment of ambient PM2. 5-bound polycyclic aromatic hydrocarbons (PAHs) in central Tehran. Environment International 120, 321-332 (2018).

38. Ahmed, E., Kim, K.-H., Shon, Z.-H. \& Song, S.-K. Long-term trend of airborne particulate matter in Seoul, Korea from 2004 to 2013. Atmospheric Environment 101, 125-133 (2015).

39. Cheng, Z. et al. Status and characteristics of ambient PM2. 5 pollution in global megacities. Environment International 89, 212-221 (2016).

40. Hu, J., Wang, Y., Ying, Q. \& Zhang, H. Spatial and temporal variability of PM2. 5 and PM10 over the North China Plain and the Yangtze River Delta, China. Atmospheric Environment 95, 598-609 (2014).

41. Guan, Q. et al. Spatio-temporal variability of particulate matter in the key part of Gansu Province, Western China. Environmental Pollution 230, 189-198 (2017).

42. Guo, B. et al. Using rush hour and daytime exposure indicators to estimate the short-term mortality effects of air pollution: A case study in the Sichuan Basin, China. Environmental Pollution 242, 1291-1298 (2018).

43. Ye, W.-F., Ma, Z.-Y. \& Ha, X.-Z. Spatial-temporal patterns of PM 2.5 concentrations for 338 Chinese cities. Science of The Total Environment 631, 524-533 (2018).

44. Henschel, S. et al. Trends of nitrogen oxides in ambient air in nine European cities between 1999 and 2010. Atmospheric Environment $117,234-241$ (2015).

45. Masiol, M., Squizzato, S., Formenton, G., Harrison, R. M. \& Agostinelli, C. Air quality across a European hotspot: Spatial gradients, seasonality, diurnal cycles and trends in the Veneto region, NE Italy. Science of The Total Environment 576, 210-224 (2017).

46. Tonse, S. R., Brown, N. J., Harley, R. A. \& Jin, L. A process-analysis based study of the ozone weekend effect. Atmospheric Environment 42, 7728-7736 (2008).

47. Askariyeh, M. H. \& Arhami, M. Projecting emission reductions from prospective mobile sources policies by road link-based modelling. International Journal of Environment and Pollution 53, 87-106 (2013).

48. Song, C. et al. Health burden attributable to ambient PM2. 5 in China. Environmental Pollution 223, 575-586 (2017).

49. Cheng, N. et al. Ground ozone concentrations over Beijing from 2004 to 2015: Variation patterns, indicative precursors and effects of emission-reduction. Environmental Pollution 237, 262-274 (2018)

50. Gao, W. et al. Long-term trend of O3 in a mega City (Shanghai), China: Characteristics, causes, and interactions with precursors. Science of The Total Environment 603, 425-433 (2017).

51. Oltmans, S. et al. Recent tropospheric ozone changes-A pattern dominated by slow or no growth. Atmospheric Environment 67, 331-351 (2013).

52. Zhao, S. et al. Annual and diurnal variations of gaseous and particulate pollutants in 31 provincial capital cities based on in situ air quality monitoring data from China National Environmental Monitoring Center. Environment International 86, 92-106 (2016).

53. Zhang, Y.-L. \& Cao, F. Fine particulate matter (PM 2.5) in China at a city level. Scientific Reports 5, 14884 (2015).

54. He, J. et al. Air pollution characteristics and their relation to meteorological conditions during 2014-2015 in major Chinese cities. Environmental Pollution 223, 484-496 (2017).

55. Seifi, M., Niazi, S., Johnson, G., Nodehi, V. \& Yunesian, M. Exposure to ambient air pollution and risk of childhood cancers: A population-based study in Tehran, Iran. Science of The Total Environment 646, 105-110 (2019).

56. Zuberi, M. J. S., Torkmahalleh, M. A. \& Ali, S. H. A comparative study of biomass resources utilization for power generation and transportation in Pakistan. International Journal of Hydrogen Energy 40, 11154-11160 (2015).

57. Ezimand, K. \& Kakroodi, A. Prediction and spatio-Temporal analysis of ozone concentration in a metropolitan area. Ecological Indicators 103, 589-598 (2019).

58. Shamsipour, M. et al. A framework for exploration and cleaning of environmental data: Tehran air quality data experience. Archives of Iranian Medicine 17, 821-829 (2014).

59. Zheng, S., Cao, C.-X. \& Singh, R. P. Comparison of ground based indices (API and AQI) with satellite based aerosol products. Science of the Total Environment 488, 398-412 (2014).

60. Jiang, L. \& Bai, L. Spatio-temporal characteristics of urban air pollutions and their causal relationships: Evidence from Beijing and its neighboring cities. Scientific Reports 8, 1279 (2018).

\section{Acknowledgements}

This research is financially supported by the National Institute for Medical Research Development; NIMAD; (grant number: 971080). We would like to thank Tehran Province Metrological Administration and Tehran Air Quality Control Company for their collaboration to provide easy access to meteorological and air quality data.

\section{Author contributions}

Mohammad Sadegh Hassanvand and Kamyar Yaghmaeian provided the idea for this work, designed the study and revised the manuscript. Sasan Faridi and Fatemeh Yousefian contributed to data gathering, performed statistical data analysis, prepared all figures and tables, and wrote the main manuscript. Mina Aghaei, Faramarz Azimi and Mansour Shamsipour contributed to the data preprocessing and analysis.

\section{Competing interests}

The authors declare no competing interests.

\section{Additional information}

Supplementary information is available for this paper at https://doi.org/10.1038/s41598-019-56578-6.

Correspondence and requests for materials should be addressed to K.Y. or M.S.H.

Reprints and permissions information is available at www.nature.com/reprints.

Publisher's note Springer Nature remains neutral with regard to jurisdictional claims in published maps and institutional affiliations. 
(c) (i) Open Access This article is licensed under a Creative Commons Attribution 4.0 International License, which permits use, sharing, adaptation, distribution and reproduction in any medium or format, as long as you give appropriate credit to the original author(s) and the source, provide a link to the Creative Commons license, and indicate if changes were made. The images or other third party material in this article are included in the article's Creative Commons license, unless indicated otherwise in a credit line to the material. If material is not included in the article's Creative Commons license and your intended use is not permitted by statutory regulation or exceeds the permitted use, you will need to obtain permission directly from the copyright holder. To view a copy of this license, visit http://creativecommons.org/licenses/by/4.0/.

(C) The Author(s) 2020 